

\title{
Differentiating electrochemically active regions of indium tin oxide electrodes for hydrogen evolution and reductive decomposition reactions. An in situ optical microscopy approach
}

Paolo Ciocci, Jean-François Lemineur, Jean-Marc Noël, Catherine Combellas, Frédéric Kanoufi

\section{To cite this version:}

Paolo Ciocci, Jean-François Lemineur, Jean-Marc Noël, Catherine Combellas, Frédéric Kanoufi. Differentiating electrochemically active regions of indium tin oxide electrodes for hydrogen evolution and reductive decomposition reactions. An in situ optical microscopy approach. Electrochimica Acta, 2021, 386, pp.138498. hal-03368484

\author{
HAL Id: hal-03368484 \\ https://hal.science/hal-03368484
}

Submitted on 6 Oct 2021

HAL is a multi-disciplinary open access archive for the deposit and dissemination of scientific research documents, whether they are published or not. The documents may come from teaching and research institutions in France or abroad, or from public or private research centers.
L'archive ouverte pluridisciplinaire HAL, est destinée au dépôt et à la diffusion de documents scientifiques de niveau recherche, publiés ou non, émanant des établissements d'enseignement et de recherche français ou étrangers, des laboratoires publics ou privés. 


\title{
Differentiating electrochemically active regions of indium tin oxide electrodes for hydrogen
} evolution and reductive decomposition reactions. An in situ optical microscopy approach.

\author{
Paolo Ciocci, ${ }^{\mathrm{a}}$ Jean-François Lemineur, ${ }^{\mathrm{a}} \mathrm{Jean}-$ Marc Noël, ${ }^{\mathrm{a}}$ Catherine Combellas, ${ }^{\mathrm{a}}$ Frédéric
} Kanoufi $^{\mathrm{a}, *}$

${ }^{a}$ Université de Paris, CNRS, ITODYS, 75006 Paris, France

\section{Corresponding author: Frédéric Kanoufi, frederic.kanoufi@u-paris.fr}

\begin{abstract}
Indium tin oxide (ITO) is an important electrode material in electrochemical studies. However, it presents some chemical and electrochemical limitations, which are often underestimated. In this work the electrochemical behavior of ITO is investigated under optoelectrochemical monitoring in a scanning electrochemical cell microscopy, SECCM, configuration during the hydrogen evolution reaction (HER) in $5 \mathrm{mM}$ of $\mathrm{H}_{2} \mathrm{SO}_{4}$, a concentration for which the ITO electrode remains stable. The in situ optical monitoring through interference reflection microscopy (IRM) allows discriminating the formation of $\mathrm{H}_{2}$ nanobubbles, NBs, and the formation of $\operatorname{In}(0)$ nanoparticles, NPs, issued from the HER and the ITO electrochemical reduction respectively. A segregation in electrode potential and space between NBs and NPs formation on the ITO electrode is observed, which is attributed to the intrinsic variation of the ITO conductivity. This variation is further evidenced by changing the droplet cell position on the ITO substrate and through SECM investigation. Besides the onset potential of the NPs formation is shifted toward less negative potentials when the conductivity of the ITO increases whereas the onset potential of the $\mathrm{H}_{2}$ formation remains mostly unchanged.
\end{abstract}


Keywords

Opto-electrochemistry, Indium Tin Oxide, Hydrogen Evolution Reaction, Nanobubbles, In(0) nanoparticles 


\section{Introduction}

Because of its high transparency and conductivity[1,2], ITO is an important electrode material in electrochemical studies and applications that take benefit of its transparent optical and electronic conductive properties [3]. It has been used in different applications or research developments related to photovoltaics [4], electrochromism [5,6], fuel cells [7], electrocatalytic devices [8,9]. Its combined optoelectronic properties makes ITO substrate an electrode material of choice allowing complementary optical or spectroscopic inspection during electrochemical processes for mechanistic or electroanalytical, or sensing [10] studies.

In the context of single entity electrochemistry such complementary optical and electrochemical inspection is of fundamental mechanistic importance [11,12] since it allowed tracking optically, from optical microscopes, the displacement [13], deformation [14], chemical conversion or transformation [15-21] of individual objects subjected to an electrochemical reaction. In this respect, ITO electrodes have been used to optically detect the electrochemical collision of various nano- or micro-particles [12,20,22,23].

Owing to its poor electrocatalytic properties, ITO stands for a pertinent support for apprehending the electrocatalytic activities of NPs for reduction such as HER, ORR and oxidation such as OER. It is thus often considered as an inert electrode in single entity (NPs) studies, for example to reveal the intrinsic electrocatalytic activity of individual NPs or to demonstrate and quantify the nucleation and growth of $\mathrm{H}_{2}$ nanobubbles, NBs, upon the HER reaction from catalytic NPs [24-26].

However, ITO also shows some chemical and electrochemical limitations, which are often underestimated. The chemical and electrochemical stability of ITO substrates strongly depends on the $\mathrm{pH}$ of the adopted electrolyte [27], as reported by many researchers for hydrochloric acid [28] and other common acids typically used as electrolytes [29,30]. Some systematical studies, reviewed in $[29,31]$, have reported the degradation of ITO under various reduction and oxidation conditions. 
In the specific context of the investigation of HER at electrocatalytic nanomaterials supported by ITO electrode, the resistance of ITO to negative potentials and acidic solution is of prime importance. Indeed, under reductive conditions, ITO was shown to be reduced into arrays of metallic NPs composed of In and Sn, the onset potential for the transformation of the ITO into metal NP depending on the solution $\mathrm{pH}$ and the anion of the electrolyte [29]. From a macroscopic point of view, this transformation is accompanied by a decrease of the electrode transparency and conductivity. Such alteration of its electronic and optical properties may then affect the electrochemical activity of ITO when used as an electrode for inspecting electrocatalytic reductive properties of individual NPs. Particularly one could question its use in opto-electrochemical studies, although such limitation or warning has not been highlighted to the best of our knowledge. This work proposes to explore such limitation under reduction conditions and particularly in the context of the opto-electrochemical monitoring of HER. The approach proposed consists in triggering the HER at ITO electrode in micrometric electrolyte droplets, in a SECCM-like configuration [32], and visualizing and discriminating by optical microscopy the fingerprint of the two competing processes: either the formation of $\mathrm{H}_{2} \mathrm{NBs}$ or the formation of metallic NPs issued from the ITO electro-reduction. Label free optical microscopies [25,26,33-35] relying on the visualization of light scattered by small objects, are indeed capable of imaging gas bubbles and NPs. The light scattering can be detected from the local variation in refractive index they produce upon their formation, by standard optical microscopy under dark field illumination [25,35], or by surface plasmon resonance $[11,34,36,37]$ or interference reflection microscopies [26,38]. The monitoring of the formation of gas bubbles or of metallic NPs by those microscopies has already been detailed. Herein, we show that those processes correspond to different optical events allowing to discriminate the optical features corresponding to each process. Such selectivity is particularly pertinent when both processes cannot be discriminated from a macroscopic electrochemical response, which includes the contribution of all nanoobjects (ensemble response). It is shown that this is typically observed when 
tuning the conductivity of the ITO electrode allowing to reveal the local heterogeneity of ITO conductivity.

\section{Experimental Section}

\subsection{Materials}

Three types of ITO coated glass coverslips $\left(22 \times 22 \mathrm{~mm}^{2}\right)$ were used with three different macroscale resistances, namely $\mathrm{ITO}_{\mathrm{h}}, \mathrm{ITO}_{\mathrm{m}}$ and $\mathrm{ITO}_{1}$ in order of increasing resistance $\mathrm{ITO}_{\mathrm{h}}<\mathrm{ITO}_{\mathrm{m}}<\mathrm{ITO}_{\mathrm{l}}$. The ITO substrates resistances, $\mathrm{R}$, were estimated by a 2-point measurement with an ohmmeter over a constant $2 \mathrm{~cm}$ distance of the samples. Unless otherwise stated, the experiments were performed with $\mathrm{ITO}_{\mathrm{h}}$. $\mathrm{ITO}_{\mathrm{h}}$ was purchased from ACM Villiers, France, $(140 \mathrm{~nm}$ thickness with $\mathrm{R}=40 \Omega)$, while $\mathrm{ITO}_{\mathrm{m}}$ and $\mathrm{ITO}_{1}$ were purchased from 2SPI, USA, respectively with indicated 30-60 $\Omega$ /square and 70-100 $\Omega$ /square sheet resistance (corresponding to ITO coating thickness of 140 and $70 \mathrm{~nm}$, respectively) and respective measured resistance of $\mathrm{R}=150$ and $500 \Omega$. The substrates were thoroughly rinsed with ethanol and dried under argon flux before characterization.

SECCM-like micro-electrochemical cells were produced by droplet confinement from micropipettes fabricated using a P2000 Laser Puller from $10 \mathrm{~cm}$ long borosilicate capillaries (1.0 $\mathrm{mm}$ of external diameter, $0.5 \mathrm{~mm}$ of internal diameter) purchased from Sutter Instrument. The pipettes were polished on aluminum oxide tape and thoroughly rinsed with milliQ water before use. Sulfuric acid of analytical grade and ferrocenemethanol, FcMeOH, 97\% were purchased from Merk and were used without any further purification.

\subsection{Opto-electrochemical experiments}

In order to study operando the reactions and modifications, which occur at ITO surfaces under negative polarization, each ITO coated glass was mounted onto the optical stage of an inverted microscope (Zeiss AxioVert), as shown in Figure 1. 


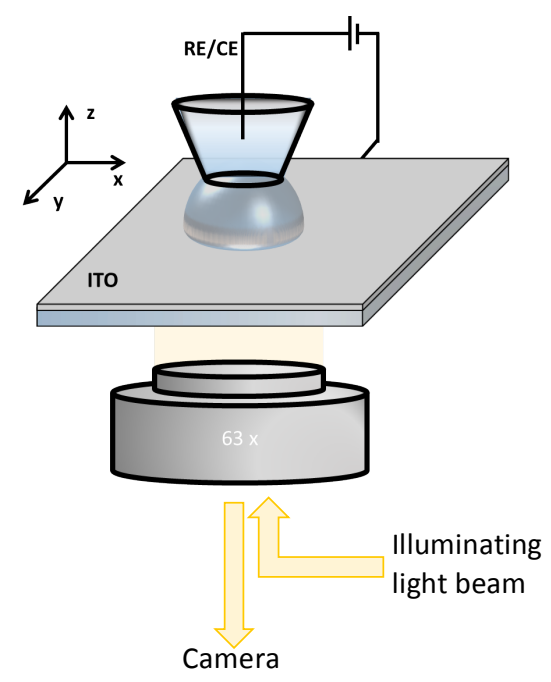

Figure 1. Schematic representation of the experimental setup for confining a micro-droplet electrochemical cell by a micropipette onto an ITO electrode surface to monitor optically by interference reflection microscopy, IRM, the ITO reduction behavior.

A light beam, from a white light source, is focused, through an oil immersion objective (x63, NA 1.4) at the upper surface of the ITO. The light reflected by this surface is then sent back (through the objective) towards an 8-bit CMOS camera. In such configuration, upon deposition of an electrolytic solution atop the ITO surface, one directly visualizes and images the ITO|electrolyte interface with a depth of field $\sim 0.4 \mu \mathrm{m}[39]$ over a typical $50 \times 50 \mu \mathrm{m}^{2}$ optically imaged region.

A tip-end capillary previously fabricated with a laser puller was filled with the electrolytic solution made of $5 \mathrm{mM} \mathrm{H}_{2} \mathrm{SO}_{4}$ aqueous solution. It was approached from the ITO surface until the meniscus of the electrolytic solution contacted the ITO, forming a droplet confined between the capillary and the ITO. Like in a SECCM configuration, the droplet forms a miniaturized electrochemical cell whose electrochemically active regions on the ITO covered glass is about 100-200 $\mu \mathrm{m}$ in diameter.

The ITO covered glass, connected to a potentiostat (CH Instruments, IJ Cambria, UK), was used as the working electrode, while a $150 \mu \mathrm{m}$ diameter Pt wire inserted in the other extremity of the capillary was used as both the counter and quasi-reference (QR) electrode of the two-electrodebased electrochemical cell. 
Cyclic voltammetry was performed at $50 \mathrm{mV} / \mathrm{s}$ while optical images were collected with a $20 \mathrm{~Hz}$ frequency by the 8-bit camera triggered synchronously to the electrochemical recording thanks to a wave generator.

In order to correct CVs for possible fluctuations in the Pt QR electrode potential, the CVs were rescaled vs. an internal potential reference assigned to the quasi-reversible ITO surface transformation (see below the CV description). This quasi-reversible system corresponds to the adsorption/desorption of sulfate ions at the ITO coated glass surface. After the ITO reduction experiments and in blank experiments, a $\mathrm{CV}$ is performed in a solution of $1 \mathrm{mM} \mathrm{FcMeOH}$ used as a molecular potential reference, the CV shows the same ITO surface quasi-reversible system and the $\mathrm{FcMeOH}$ oxidation, allowing to rescale the apparent $\mathrm{E}^{0}$ value of the quasi-reversible system, estimated from the median between the anodic, $\mathrm{E}_{\mathrm{a} 1}$, and cathodic, $\mathrm{E}_{\mathrm{c} 1}$, peak potentials, $\mathrm{E}^{0}=$ $\left(\mathrm{E}_{\mathrm{a} 1}+\mathrm{E}_{\mathrm{c} 1}\right) / 2=-0.23 \pm 0.02 \mathrm{~V}$ vs the $\mathrm{E}^{0}$ of the reversible $\mathrm{FcMeOH}^{+} / \mathrm{FcMeOH} \mathrm{couple}$.

\subsection{Optical data processing}

Principle of the optical detection. The general operating principle of Interference Reflection Microscopy (IRM) has been described elsewhere [17,26,38]. Briefly, the imaging process is based on the collection of the light reflected by the different interfaces crossed by the light beam. The amplitude and phase of this reflected plane wave, and therefore the intensity of reflected light, are generally depicted by Fresnel laws for macroscopic interfaces. When a nanosized pattern appears on such interfaces, it is expected to scatter light, redirecting waves in all directions of space. The image recorded on the camera is then a combination (interference) of the reflected plane wave, of electric field $E_{r e f}$, and the spherical wave (back)scattered, $E_{s c a t}$, towards the microscope objective. Depending on the nature of the interference (constructive or destructive), the optical spots intensity 
associated to local variation in refractive index can be, respectively, brighter or darker than the background. The optical intensity collected at each position of space, $r$, can be expressed by:

$I(\boldsymbol{r}) \propto\left|\boldsymbol{E}_{\text {ref }}(\boldsymbol{r})\right|^{2}+\left|\boldsymbol{E}_{\text {scat }}(\boldsymbol{r})\right|^{2}+2\left|\boldsymbol{E}_{\text {ref }}(\boldsymbol{r})\right|\left|\boldsymbol{E}_{\text {scat }}(\boldsymbol{r})\right| \cos \theta_{r s}$

where $\theta_{\mathrm{rs}}$ is the phase angle between the scattered and the reflected light. This equation explains the enhancement of sensitivity of IRM, which is sensitive to the product between the electrical fields of reflected wave and scattered one. Indeed, while the scattered cross section of nanopatterns, e.g. described by Mie theory or collected in transmission dark-field microscopies, is usually proportional to the square of the electric field, $\left|E_{\text {scat }}(\mathrm{r})\right|^{2}$, and scales as the square of the nanopattern volume, the optical intensity collected by IRM rather scales with the volume of the nanofeatures.

Moreover, in the absence of nanopatterns, the background optical image is due to the amount of light reflected by the interface and is proportional to $\left|E_{\text {ref }}\right|^{2}$. It means that the electrode|electrolyte interface is visible and that IRM offers conditions to image macroscale (with sub-micrometric resolution) electrode processes.

Image analysis. The background intensity of the IRM measurement, denoted $I_{b k g}$, corresponds to the amount of light reflected by the ITO|electrolyte interface. It is evaluated by averaging the pixels intensity over regions of the optical images (at least $>5 \times 5$ pixels) where the NBs and the NPs are not detected.

A dynamic superlocalization approach was performed to characterize each optical pattern or spot present on a given image. Briefly, it consists in locating the intensity centroid of the point spread function associated to each optical pattern or spot by using the Crocker and Grier centroid-finding algorithm [40]. Such procedure allows estimating the position $(\mathrm{x}, \mathrm{y})$ of the center of mass of the optical pattern with $10 \mathrm{~nm}$ resolution in the focal plane. The optical intensity at this position, namely $I_{\text {opt, }}$ is then obtained by calculating the mean pixels intensity of a square (a total of 16 pixels) centered at the $(\mathrm{x}, \mathrm{y})$ position. Image analysis was performed by home-programmed Python 
routines integrating functions of the Trackpy Python package [41]. The evolution of background subtracted $\mathrm{I}_{\mathrm{opt}}$ for a same optical pattern along different images produces optical transients $\left(\mathrm{I}_{\mathrm{opt}} \mathrm{t}^{\mathrm{t}}\right)$. Recast along the electrode potential, E, opto-voltammograms $\mathrm{I}_{\mathrm{opt}} \mathrm{E}$ were drawn. To account for the variability in the optical transients recorded for the different optical patterns (usually $>100$ patterns detected over the imaged area), the transients were analyzed statistically to discuss the median, firstquartile and third-quartile of their distribution.

\subsection{Electron microscopy imaging}

Electron microscopy images were recorded using a Zeiss SUPRA 40 SEM-FEG scanning electron microscope (SEM) with an accelerating voltage of $3 \mathrm{kV}$.

\subsection{Scanning electrochemical microscopy}

SECM setup and ultramicroelectrodes (UMEs) preparation. SECM experiments in unbiased feedback mode (the ITO electrode was not electrically connected) were performed using a SECM setup from $\mathrm{CH}$ Instruments (Model \#910B, Austin, Texas, USA) in a 3-electrode configuration using a $\mathrm{Pt}$ wire $\mathrm{CE}$ and a $\mathrm{Ag} / \mathrm{AgCl}$ wire $\mathrm{RE}$. Homemade $\sim 5 \mu \mathrm{m}$ radius microelectrodes were fabricated using $1.0 \mathrm{~mm} / 0.5 \mathrm{~mm}$ (inner /outer diameter) borosilicate glass capillaries from Sutter Instruments (Novato, California), $25 \mu \mathrm{m}$ diameter Pt wires (99.99\%, Goodfellow Cambridge Ltd., Huntingdon, England), and a laser puller from Sutter (Model\# p-2000, Novato, CA, USA). They were then polished using diamond polishing pads obtained from Precision Surface Instruments Inc. (www.psidragon.com, Houston, Texas, USA) on a micro polishing system from Sutter. The ratio of external glass diameter to the electrode radius $(\mathrm{Rg})$ was confirmed by performing an approach curve on an insulating glass slide in a $0.1 \mathrm{M} \mathrm{KCl}$ solution containing $1 \mathrm{mM}$ ferrocenemethanol $(\mathrm{FcMeOH})$.

SECM experimental procedure. Briefly an SECM approach curve consists in recording the normalized current $I=i / i_{\text {inf }}$ as a function of the normalized distance $L=d / a ; i$ is the current recorded at the $\mathrm{UME}$ that is biased at $0.3 \mathrm{~V}$ vs $\mathrm{Ag} / \mathrm{AgCl}$ to ensure a mass-transfer limited current, 
$i_{\text {inf }}$ the steady state current recorded when the SECM tip is at infinite distance from the ITO electrode, $d$ is the tip-ITO distance and $a$ the tip radius. Once the steady state is reached, the UME is approached at $1 \mu \mathrm{m} \cdot \mathrm{s}^{-1}$. The zero-distance $(\mathrm{d}=0)$ as well as the feedback character of the approach curves, characterized by the dimensionless charge transfer rate constant, $\mathrm{K}$, which reflects the reaction rate between the reduced redox probe and the surface under analysis, were determined from adjustments between the experimental approach curves and dimensionless theoretical curves [42-44]. The SECM image was acquired after retracting the SECM tip by $\sim \mu \mathrm{m}$ from the contact point position and scanning in the $\mathrm{x}-\mathrm{y}$ direction at a scan rate of $100 \mathrm{mV} . \mathrm{s}^{-1}$.

\section{Results and Discussion}

3.1. Monitoring the $\mathrm{H}^{+}$-induced degradation of ITO optical properties

In the context of the visualization of HER at ITO electrodes one needs considering the stability of ITO substrates under acidic conditions. A degradation process, usually irreversible, occurs in extremely acidic conditions $(\mathrm{pH}<1)$, without need of applied potential. It consists of the chemical dissolution of oxides, $\mathrm{In}_{2} \mathrm{O}_{3}$ and $\mathrm{SnO}_{2}$, recognizable from uniform variations in optical properties such as the substrate absorbance or, as detected by IRM or other optical microscopies, from variations in the background intensity, $I_{b k g}$. In standard lithographic techniques $>1 \mathrm{M} \mathrm{HCl}$ solutions are generally used to etch and pattern ITO coatings with etching rates of the order of several $\mathrm{nm} / \mathrm{min}$ [45]. Solutions of other acids at lower concentration may be used to operate the dissolution of ITO. If often unsuspected because undetected in situ by optical techniques, the enhanced optical sensitivity of IRM allows monitoring such subtle variations in the optical transparency of ITO coatings. In this respect, Figure 2 shows the evolution of the light reflected by the ITO|electrolyte interface collected by IRM with the time of contact of droplets composed of $5 \mathrm{mM}$ to $1 \mathrm{M} \mathrm{H}_{2} \mathrm{SO}_{4}$ electrolyte. 
These measurements were performed for a $70 \mathrm{~nm}$ thick ITO coating in the absence of electrode polarization. They correspond to the time evolution of $I_{b k g}$ that would be recorded in situ during typical IRM monitoring of an electrochemical reaction. The action of acidic solution on $I_{b k g}$ is characterized by a two-step process. In the first instants $I_{b k g}$ decreases slowly until, in a second period, it vanishes abruptly, suggesting the ITO coating gets completely removed. The overall process takes ca. $250 \mathrm{~s}$ in a $1 \mathrm{M} \mathrm{H}_{2} \mathrm{SO}_{4}$ solution, which is in the range of the approx. $16 \mathrm{~nm} / \mathrm{min}$ etching rate observed in $2 \mathrm{M} \mathrm{HCl}$ solutions [45]. Decreasing the acid concentration decreases the slopes of the first and second stages of $I_{b k g}$ variations. For $5 \mathrm{mM} \mathrm{H}_{2} \mathrm{SO}_{4}$, indeed $I_{b k g}$ does not change by less than $1 \%$ within 20 min, suggesting that the ITO surface can be considered stable during most electrochemical studies in such conditions. Noteworthy, when HER reactions are considered, such low $\mathrm{H}^{+}$content limits the amount of $\mathrm{H}_{2}$ that can be evolved and therefore the number of gas bubbles that can be generated at the surface.



Figure 2. Evolution with time of the background intensity, $I_{b k g}$, recorded by IRM for a $70 \mathrm{~nm}$ ITO layer contacted with micrometer size droplet of $\mathrm{H}_{2} \mathrm{SO}_{4}$ solutions.

3.2. Monitoring in situ the reduction behavior of ITO electrodes 
The reduction behavior of ITO electrodes depends on different chemical and physical parameters such as the electrode conductivity (related to the ITO coating thickness) [46], the $\mathrm{pH}[30]$ and chemical composition of the electrolyte [47], the In:Sn ratio, the coating porosity and roughness[1]. ITO is usually considered as an inert substrate. However, surface processes such as coating reconstruction, nanoscale defects formation (such as NPs) have been described [48] and are usually detected by ex situ SEM imaging. We propose herein to probe operando the reduction behavior of ITO coating using IRM monitoring during cyclic voltammetry experiments. As will be discussed later, by using three ITO substrates named $\mathrm{ITO}_{\mathrm{l}}, \mathrm{ITO}_{\mathrm{m}}$ and $\mathrm{ITO}_{\mathrm{h}}$ of increasing coating thickness and therefore increasing conductivity, this behavior depends on the conductivity of the ITO coating. The general overview of the situations encountered and of the experimental methodology used is first described, in Figure 3, in the case of the most conductive one, $\mathrm{ITO}_{\mathrm{h}}$.

Figure 3a shows the cyclic voltammogram of the $\mathrm{ITO}_{\mathrm{h}}$ electrode contacted with a ca. $200 \mu \mathrm{m}$ diameter droplet of $5 \mathrm{mM} \mathrm{H}_{2} \mathrm{SO}_{4}$ electrolyte confined by a micropipette equipped with a $\mathrm{Pt}$ wire used as both QR and counter electrode. A first quasi-reversible system enlarged in the inset of Figure $3 \mathrm{a}$ is detected. It corresponds to two bell-shaped reduction and oxidation peaks of equivalent charges, respectively at $\mathrm{E}_{\mathrm{c} 1}$ and $\mathrm{E}_{\mathrm{a} 1}$, assigned to sulfate ions adsorption/desorption. This quasireversible system is present on all CVs, and its apparent $E^{0}=\left(E_{c 1}+E_{a 1}\right) / 2$ is unchanged, whatever the ITO conductivity compared to an external potential reference such as the $\mathrm{E}^{0}$ of FcMeOH. All CVs are then rescaled vs the $\mathrm{E}^{0}$ of this quasi-reversible system. Towards more negative potentials, two other reduction processes are detected with onset potential at respectively -0.8 and $-1.05 \mathrm{~V}$.

Optical images of the ITO|electrolyte interface were recorded with a $20 \mathrm{~Hz}$ frequency synchronously with the CV; some examples images obtained at $0.3,-0.95$ and $-1.2 \mathrm{~V}$ are given in Figure $3 \mathrm{~b}$. Compared to the first image at $0.3 \mathrm{~V}$, optical patterns have appeared on the latter two images concomitantly to the onset of the cathodic current flows. 
A dynamic superlocalization approach in every image frame allowed counting the number of patterns, N, per image along the electrode potential evolution (see Figure $3 \mathrm{c}$ ) and characterizing every optical pattern through the position $(\mathrm{x}, \mathrm{y})$ and optical intensity, $I_{\text {opt }}$, of its center of mass (see Experimental section). On the negative scan, $\mathrm{N}$, as for the $\mathrm{CV}$, presents two successive onsets of pattern appearance: a sharp increase in $\mathrm{N}$ occurs around $-0.83 \mathrm{~V}$, followed by a second increase at $1.19 \mathrm{~V}$. On the reverse oxidation potential scan two sharp decreases in $\mathrm{N}$ are also detected at -1.14 and $-0.49 \mathrm{~V}$ respectively.
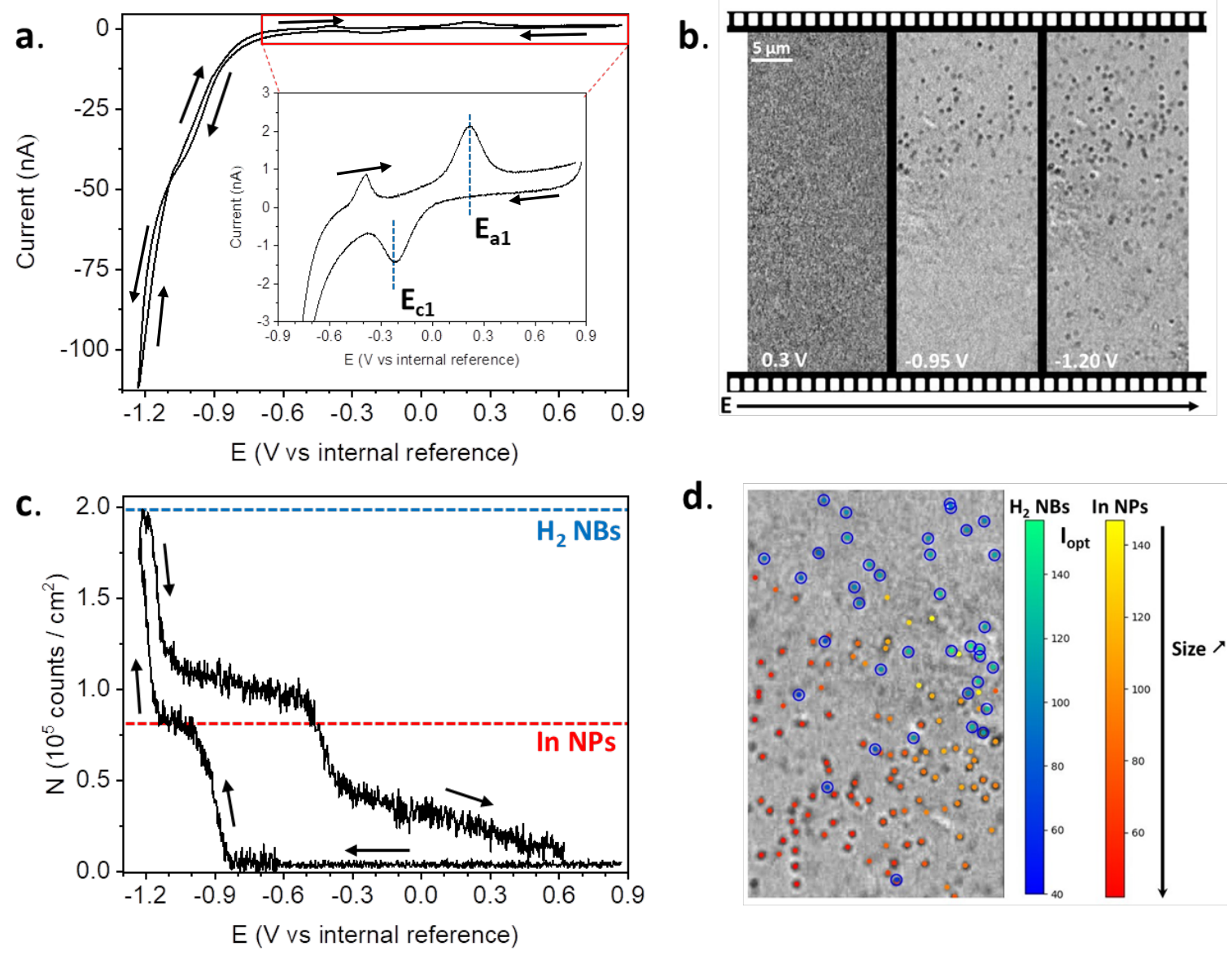

Figure 3. Illustration of the opto-electrochemical investigation of the electrochemical behavior of an ITO electrode contacted with a $5 \mathrm{mM} \mathrm{H}_{2} \mathrm{SO}_{4}$ micrometric electrolyte droplet confined at the tip of a micropipette. a) Cyclic voltammogram of a ca. $200 \mu \mathrm{m}$ diameter droplet of electrolyte recorded when in contact with the $\mathrm{ITO}_{\mathrm{h}}$ substrate $\left.(\mathrm{v}=50 \mathrm{mV} / \mathrm{s}) . \mathrm{b}\right)$ Examples of sequential optical images recorded at different electrode potentials showing the successive formation of optical patterns. c) The number $\mathrm{N}$ of optical patterns detected 
at each image along with electrode potential identifies two regions of potentials and the formation of two populations of patterns associated, respectively, to the reduction of ITO into $\operatorname{In}(0)$ and the formation of $\mathrm{H}_{2}$ NBs. d) Reconstructed image showing how each pattern population grows selectively on different regions of the $\mathrm{ITO}_{\mathrm{h}}$ electrode, the colorbars provide a qualitative comparison of the difference in size of the nanopatterns in each population.

The optical spots observed on the different images are all characterized by diffraction-limited patterns, suggesting they correspond to the formation of sub-wavelength objects whose footprint on the electrode is $<300 \mathrm{~nm}$ based on previous modeling of the optical response of sphere cap-type nanoobjects [26]. The appearance and disappearance of these features in two different potential regions suggests that two populations of nanoobjects are formed on the ITO with two different chemical compositions and natures.

These two nanoobjects populations were further discriminated based on their optical features (see Figure 3d). Indeed, it has been noted that the two populations are distinct when considering i) their optical transients, ii) their characteristic (median) onset potentials of patterns appearance during the forward potential scan and disappearance during the reverse scan and, iii) nanoscale motion. The characteristics and identification of each of these populations are discussed in the next sections. They are associated to either the reduction of ITO into metallic NPs of $\operatorname{In}(0)$ and the evolution of $\mathrm{H}_{2}$ NBs from HER.

\subsection{Hydrogen nanobubbles nucleation}

Tracking the steps and mechanisms of hydrogen NBs nucleation and growth on a large variety of interfaces and NPs is fundamental for validating theoretical models related to heterogeneous nucleation and gaining insights on how NBs can affect the efficiency of devices' catalysts. Quantifying and following operando the hydrogen NBs growth on bare ITO is interesting not only to distinguish NBs optical footprint from the one related to ITO reduced NPs, but also to gain a statistically significative reference signal in order to compare kinetic parameters of non-catalyzed 
$\mathrm{H}_{2}$ nucleation from catalyzed one. The growth mechanism of $\mathrm{H}_{2}$ bubbles can be investigated with a high throughput quantitative analysis thanks to IRM high sensitivity probing $(<20 \mathrm{~nm})$, as previously achieved by our group for $\mathrm{H}_{2}$ NBs nucleation on Pt NPs under similar conditions in 5 $\mathrm{mM} \mathrm{H}_{2} \mathrm{SO}_{4}$ electrolyte [26].

\section{a.}

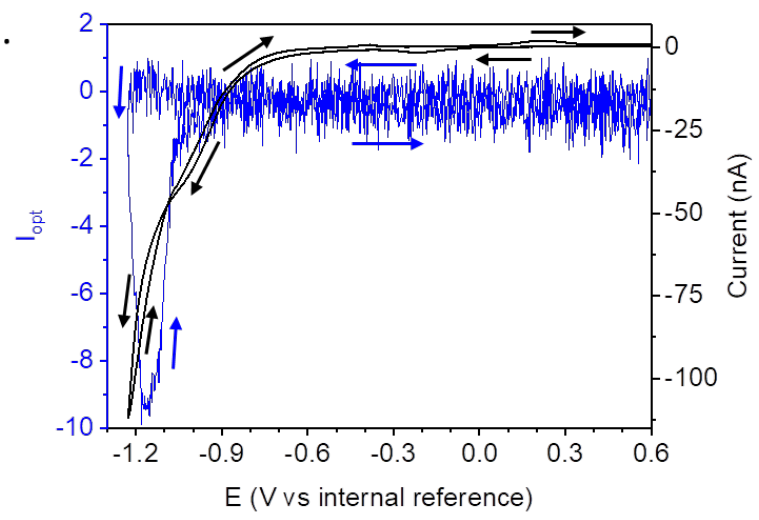

b.
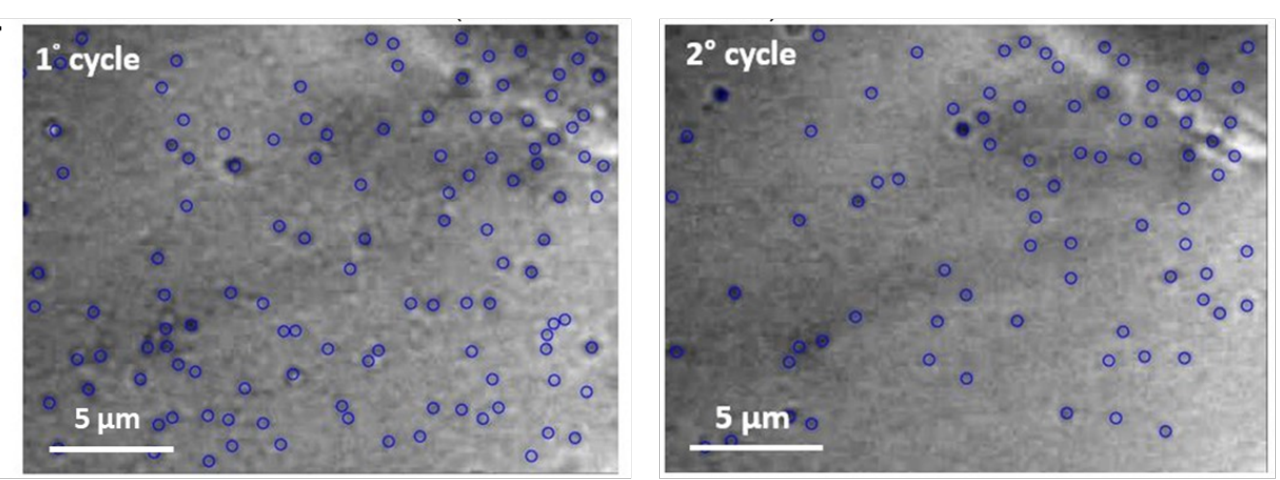

c.
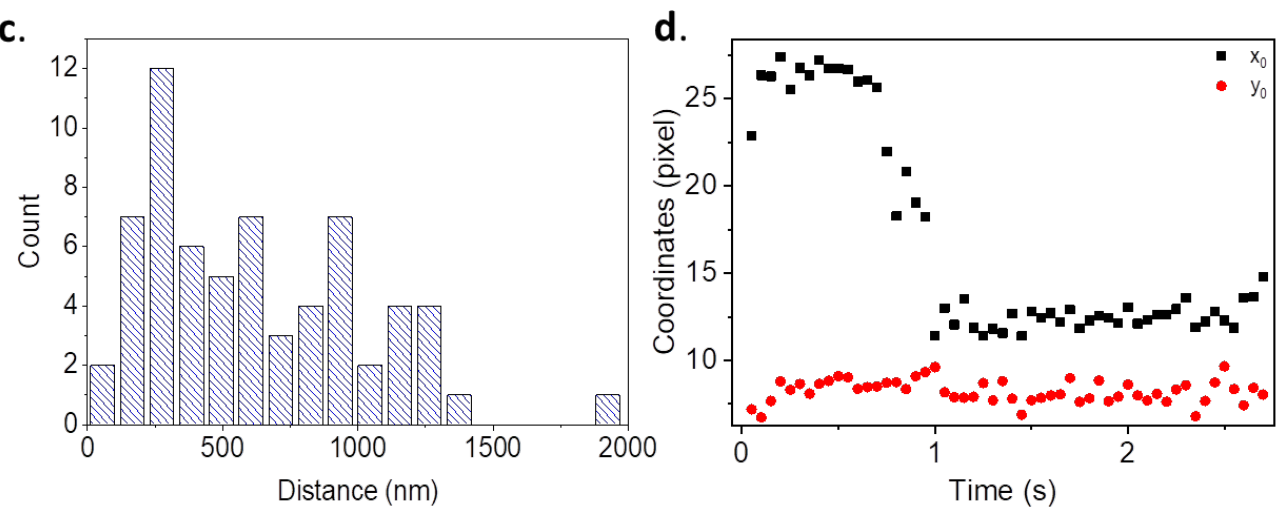

Figure 4. a) Median of the distribution of optical voltammograms, $\mathrm{I}_{\mathrm{opt}}-\mathrm{E}$ curves, recorded from the patterns appearing at $\mathrm{E}<-1.1 \mathrm{~V}$ and corresponding to the formation of $\mathrm{H}_{2} \mathrm{NBs}$ in a $5 \mathrm{mM} \mathrm{H}_{2} \mathrm{SO}_{4}$ confined electrolyte droplet together with $\mathrm{CV}$ at $50 \mathrm{mV} / \mathrm{s}$. b) Positions related to $\mathrm{H}_{2} \mathrm{NBs}$ along two consecutive voltammetric 
cycles. c) Histogram of the distribution of distances between the NBs patterns along consecutive images. d) Evolution with time of the position of a single $\mathrm{H}_{2} \mathrm{NB}$ (grown during the $\mathrm{CV}$ experiment).

Figure 4a shows the median optical transients, presented as opto-voltammograms i.e. $\mathrm{I}_{\mathrm{opt}} \mathrm{E}$ curves, of the distribution of $>100$ patterns appearing in the $\mathrm{E}<-1.1 \mathrm{~V}$ region. This electrochemical signature is related to the proton reduction and the formation of $\mathrm{H}_{2} \mathrm{NBs}$ upon HER. In the absence of Pt nanocatalysts, even if ITO is not a catalyst of HER, $\mathrm{H}_{2} \mathrm{NBs}$ were also produced here directly at the ITO electrode by HER, but at a more negative potential, $\mathrm{E}<-1.19 \mathrm{~V}(\mathrm{E}<-1.42 \mathrm{~V}$ vs $\left.\mathrm{FcMeOH}^{+} / \mathrm{FcMeOH}\right)$.

Despite the high sensitivity of IRM for gas bubbles detection, the onset of detection of NBs is shifted compared to the onset potential observed electrochemically in the CV for proton reduction. Indeed, while the latter starts around $-1.05 \mathrm{~V}$, no bubbles are observed until overcoming a local critical concentration of dissolved $\mathrm{H}_{2}$. This corresponds to conditions to reach the saturation of the electrode surface with $\mathrm{H}_{2}$ in order to initiate the nucleation of NBs on the ITO surface, as demonstrated in different systems related to HER from Pt nanoelectrodes or other catalytic NPs $[26,49,50]$. It is then expected that NBs are produced under $\mathrm{H}_{2}$ mass transfer control, while the formation of ITO reduced NPs is rather driven by a surface transformation process.

Besides the longer delay between the onsets of the electrochemical current and of the corresponding optical patterns expected for the formation of NBs compared to solid NPs, the optical patterns related to $\mathrm{H}_{2}$ NBs can be distinguished from ITO reduced NPs based on the different dynamics of their positions on the ITO surface.

These differences can be related to difference in the nucleation and growth of gas NBs or solid NPs on surfaces. On one hand, contrary to the formation of metallic NPs that produces rather immobile nuclei when their size is $>5 \mathrm{~nm}$ [51], the nucleation of gas NBs implies more mobile molecules with much higher surface diffusion. On the other hand, these processes differ from the energetics of their 
activation barrier. For NBs nucleation, this is mostly governed by the formation of the gas/liquid/solid triple-interface, i.e. the wetting of the ITO surface by the electrolyte. The activation barrier $[36,49,52]$ is then much smaller than that required for solid phase transformation. While the former is influenced by rather low surface energy variations (chemical defects) [36], the latter requires larger energies usually controlled by the electrode potential. Overall, NBs present higher mobility than NPs.

The dynamics of the nanoobjects was revealed in situ by optical microscopies [16], in the first instance by comparing the positions of the optical patterns formed at the ITO surface along different cycles of a same CV, as shown for NBs for two consecutive cycles in Figure 4b. When comparing the images recorded in the same region at the same potential NBs appear in random positions and at different locations between consecutive potential cycles, as expected for low activation barrier energy process. This is best described quantitatively by evaluating from such images the position of any given optical pattern observed during the second $\mathrm{CV}$ and comparing it to the position of the closest pattern detected in the same region but on the first $\mathrm{CV}$. The histogram provided in Figure 4c shows the distribution of distances between these patterns along consecutive images. From such distribution, the distance between NBs along consecutive cycles are $>100 \mathrm{~nm}$ for $98 \%$ of detected NBs and yield a $<2 \%$ probability to find a NB on the same nucleating site along two successive cycles.

In the second instance, the pinning of NBs relies on the presence of geometrical defects on surfaces [53]. Henceforth during its growth, a NB may find a site of higher pining energy. It is then expected that growth and dissolution of NBs are not symmetric processes [37], unlike for the growth/dissolution of NPs; indeed, the position of the center of mass of the NB may vary during the dynamics of its growth and dissolution. An example of such trajectory of the center of mass of NB during its growth/dissolution is presented in Figure 4d. It shows that during this stage the NB center of mass can move by ca. 13 pixels, i.e. by ca. $700 \mathrm{~nm}$. 


\subsection{ITO reduced NPs formation}

The onset of appearance of the other population of patterns observed in Figure 2 and highlighted in Figure 5a is associated to a decrease of $\mathrm{I}_{\mathrm{opt}}$ at $\mathrm{E} \sim-0.8 \mathrm{~V}$. It is followed by a return of $\mathrm{I}_{\mathrm{opt}}$ to the background level in the reverse scan, which occurs concomitantly to a bell-shaped oxidation peak at $-0.39 \mathrm{~V}$. Owing to its surface-limited electrochemistry, this optical transient behavior is attributed to the reduction of $\mathrm{In}(\mathrm{III})$ into metallic $\mathrm{In}(0) \mathrm{NPs}$. Indeed, the electroreduction of $\operatorname{In}_{2} \mathrm{O}_{3}$ and $\mathrm{SnO}_{2}$ can be described by two possible reactions (2) and (3) yielding to the formation of metals NPs:

$\mathrm{In}_{2} \mathrm{O}_{3}+6 \mathrm{H}^{+}+6 \mathrm{e}^{-} \rightarrow 2 \mathrm{In}+3 \mathrm{H}_{2} \mathrm{O}$

$\mathrm{SnO}_{2}+4 \mathrm{H}^{+}+4 \mathrm{e}^{-} \rightarrow \mathrm{Sn}+2 \mathrm{H}_{2} \mathrm{O}$

However, previous works [29] demonstrated from ex situ analysis by SEM and X-ray Photoemission Spectroscopy (XPS) that ITO reduced NPs are composed mainly of $\operatorname{In}(0)$. This process is partly reversible, the oxidation peak at $-0.39 \mathrm{~V}$ in Figure $5 \mathrm{a}$ being assigned to the reoxidation of $\operatorname{In}(0)$ into $\operatorname{In}(\mathrm{III})$, even if its reduction counterpart cannot be clearly identified on the CV.

The formation of metallic NPs upon ITO reduction is also demonstrated by ex situ SEM analysis performed in regions where the reduction exploration was stopped at $\mathrm{E} \sim-1.0 \mathrm{~V}$. As shown in Figure $5 \mathrm{~b}$, ITO reduced NPs were detected by SEM; they have an average diameter of ca. $120 \mathrm{~nm}$ from the dispersion size graph in the inset. Surface morphology of untreated ITO film was evaluated from high magnification SEM images (not shown). The bare ITO surface is composed by grains with an average diameter $\sim 20 \mathrm{~nm}$ and is completely exempt of NPs. A consistent amount of few particles $\left(<0.7 / \mu \mathrm{m}^{2}\right)$ aggregates is also present, as well as non-spherical NPs after sweeping the potential. 

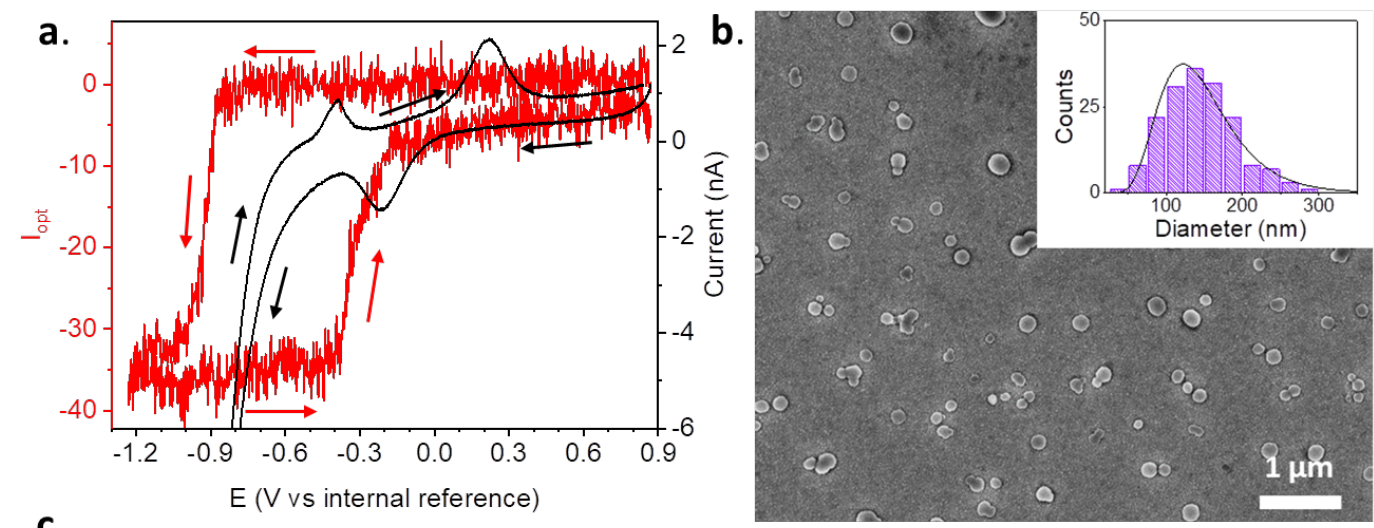

C.


d.

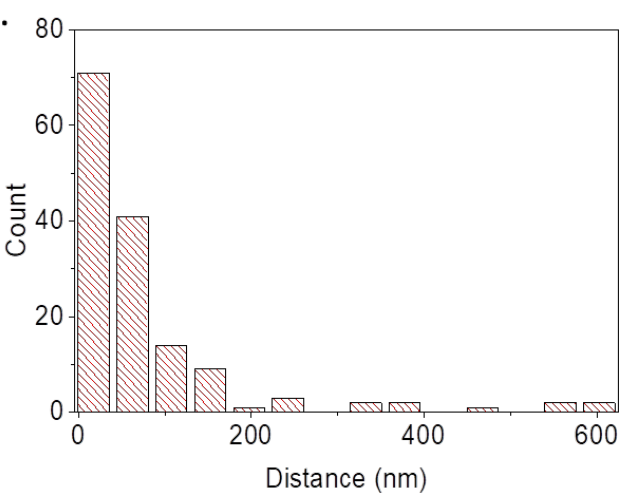

e.

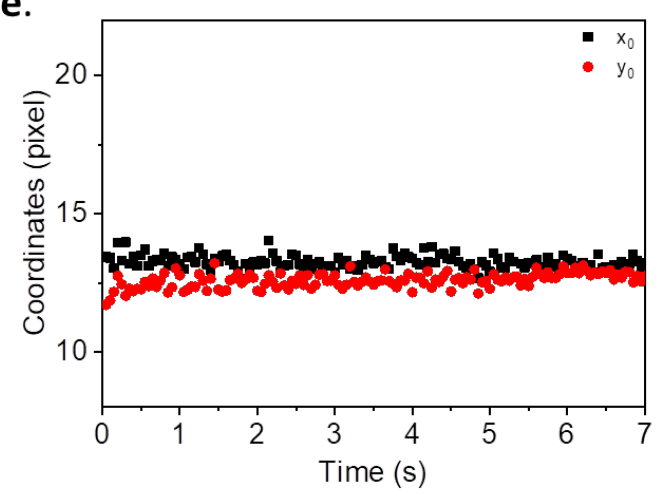

Figure 5. a) Median of the distribution of optical voltammograms, $I_{o p t}-E$ curves, recorded from the patterns corresponding to the reduction of ITO into metal In(0) NPs (red trace) during the cyclic votammogram recorded in Figure 3a (black trace). b) SEM image of ITO reduced NPs with the corresponding particle size distribution. c) Optical images related to ITO reduced NPs along two consecutive voltammetry cycles; the green spots correspond to ITO reduced NPs appearing only during the second cycle. d) Histogram of the distribution of distances between the NBs patterns along consecutive images. e) Evolution with time of the position of a single ITO reduced NP recorded during the CV experiment. 
The dynamics of the NP formation, monitored by IRM, evidences further differences between the NPs and NBs formation. Indeed, as seen in the optical images of Figure 5c, when running successive potential cycles, most NPs appear on reduction scans and disappear on the reverse oxidation scans in exactly the same positions and new NPs (in green) appear on new positions in the second cycle. The reappearance of NP at identical position along successive cycles is quantitatively demonstrated from the same parameter evaluating the distance between NPs along cycles (see Figure 5d). On the contrary to NBs this distribution is narrowed towards zero. On the basis of the observed distribution $>84 \%$ NPs are reallocated on the same positions within $<100 \mathrm{~nm}$ error. Additionally, the analysis of the displacement of the NPs center of mass during their growth/dissolution, as exemplified in Figure 5e, confirms that the NPs are rather static all along the process, which is not the case for the NBs (see Figure 4d).

Besides, the optical transients show that a small percentage of the patterns associated to ITO reduced NPs does not re-oxidize (and vanish) during the reverse potential scan. This could be due to the chemical dissolution of some of these NPs, in agreement with previous works [29]. In this case, a hole is left in place of the previously formed ITO reduced NP, eventually useful for electrodepositions in such positions. Optically, these holes are detected, as for the $\mathrm{H}^{+}$-induced dissolution of ITO, as regions of lower intensity (darker contrast) than the original surface.

\subsection{Heterogeneity of surface reactivity}

As also demonstrated by previous XPS analysis [29,54,55], ITO surface consists of a complex nonstoichiometric microstructure: parameters such as local variation of $\mathrm{In}$ :Sn ratio, surface and nearsurface density defects (e.g. oxygen vacancies, substitutional $\mathrm{Sn}^{4+}$ or interstitial $\mathrm{In}$ ) and grain boundaries orientation can influence locally the ITO electrochemical response. In this respect, the onset potential related to the ITO surface reduction can be shifted depending on surface heterogeneities, and is therefore expected to be strongly dependent on the ITO surface conductivity. 
Such effect of the ITO conductivity, summarized in Table 1, was first investigated by depositing electrolyte droplets in the SECCM-like configuration over different regions of the same most conductive $\mathrm{ITO}_{\mathrm{h}}$ substrate. The opto-electrochemical monitoring of their reduction behavior shows variety in the opto-electrochemical responses. As an example, Figure 6a presents the CV and overlaid opto-voltammogram of one of the most reactive regions explored. The electrochemical response shows that the ITO reduced NPs formation is associated to a reversible surface process with reduction and oxidation peaks at -0.58 and $-0.25 \mathrm{~V}$, respectively. Optical patterns also appear on the IRM images, as those presented in Figure 5c, with onset of appearance and of disappearance in correspondence with the ITO reduction and re-oxidation peaks, respectively. Unlike in Figure 5, the $\mathrm{I}_{\mathrm{opt}}$ values in Figure 6a exhibit a positive contrast compared to the optical background suggesting that on this explored region, larger NPs are formed [56]. Indeed, the sign of the optical contrast is related to the refractive index and size of the nanoobject and owing to the interferometric nature of the IRM small nanoobjects appear as dark (negative contrast) optical patterns while larger nanoobjects appear as bright patterns.

The heterogeneous conductivity of ITO substrates was further confirmed by SECM in unbiased feedback mode using $\mathrm{FcMeOH}$ as a redox probe and a $\sim 10 \mu \mathrm{m}$ diameter disk Pt ultramicroelectrode (UME). Such experiment actually probes the ability of the ITO surface to drive a reduction reaction (the reduction of the tip-electrogenerated $\mathrm{FcMeOH}^{+}$) and thus reflects its conductivity. The 200x200 $\mu \mathrm{m}^{2}$ area SECM image acquired at $\sim 5 \mu \mathrm{m}$ distance from the $\mathrm{ITO}_{\mathrm{h}}$ electrode (Figure 6b) shows a contrasted feedback current due to the inhomogeneous regeneration of $\mathrm{FcMeOH}^{+}$at the $\mathrm{ITO}_{\mathrm{h}}$ surface. In regions 1 and 2 (Figure $6 \mathrm{~b}$ ), these variations were quantitatively analyzed by SECM approach curves (Figure 6c). The latter indicate the coexistence between regions with negative feedback close to or surrounded by areas with positive feedback with adimensional charge transfer, K, extracted from the theoretical fit [44], which varies $\sim 5$ times from one region to another one. These results confirm that ITO may show relatively large regions $(>50 \mu \mathrm{m})$ of contrasted 
electronic conductivities. Moreover, these conductivity heterogeneities can also explain the segregation of the NBs and NPs regions that can be observed in Figure 2.



b.

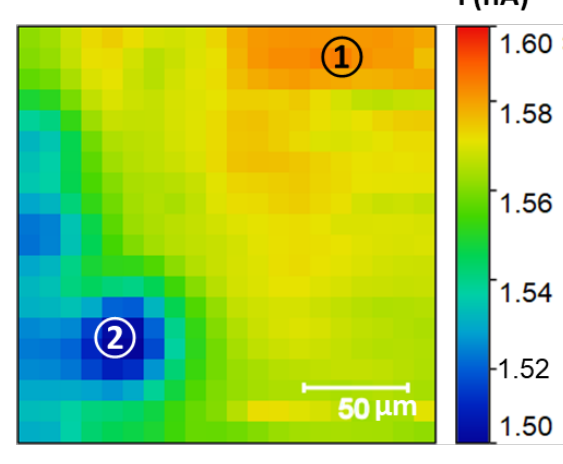

c.

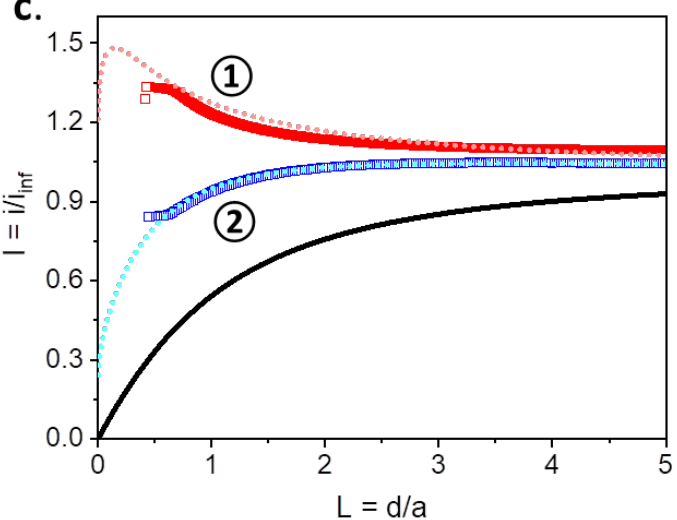

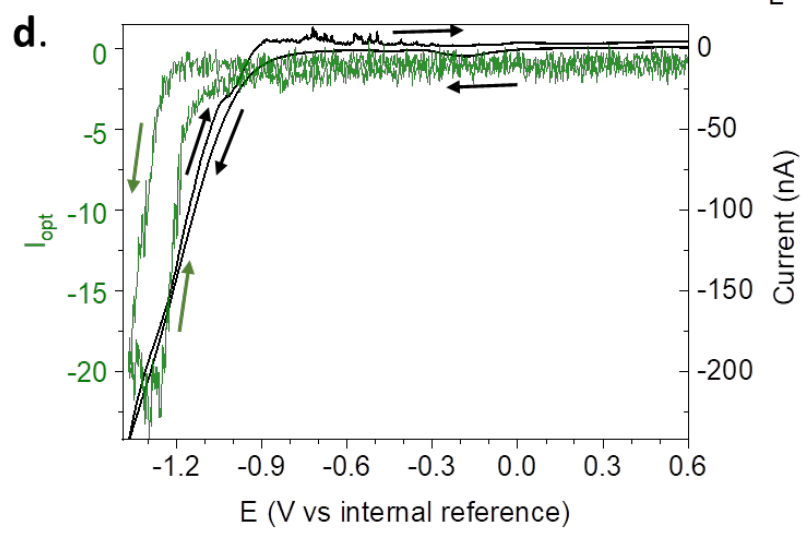

Figure 6. a) Cyclic voltammetry at $50 \mathrm{mV} / \mathrm{s}$ in a $5 \mathrm{mM} \mathrm{H}_{2} \mathrm{SO}_{4}$ confined electrolyte droplet (black trace) with median optical intensity variation related to a population of $\mathrm{ITO}_{\mathrm{h}}$ reduced $\mathrm{NPs}(\mathrm{N}>100$, red trace). b) SECM image and c) approach curves on the ITO substrate using $\mathrm{FcMeOH}$ as redox probe. The image was obtained with a scan rate of $100 \mathrm{mV} / \mathrm{s}$ at a $\sim 5 \mu \mathrm{m}$ tip-substrate distance and the approach curves at $1 \mu \mathrm{m} / \mathrm{s}$. The best theoretical fits (dot traces) of the approach curves were found using for the adimensional charge tranfer constant: $\mathrm{K}=1.4$ (1) and $\mathrm{K}=0.3$ (2); the black trace is the theoretical curve for the pure negative feedback. $\mathrm{d}$ ) 
Cyclic voltammetry (black trace) and corresponding optical voltammetry ( $\mathrm{N}>100$, green trace) as in a) performed at a lower conductive ITO substrate, ITO $_{1}$.

This conductivity effect was further investigated on a less conductive $\mathrm{ITO}_{1}$ electrode (resistance of $500 \Omega$ ). The $\mathrm{CV}$ of the $5 \mathrm{mM} \mathrm{H}_{2} \mathrm{SO}_{4}$ droplet solution on the ITO electrode and the associated median optical transient are provided in Figure 6d. Interestingly, no ITO reduced NPs were detected and the onset potential of NBs formation, ca. $-1.25 \mathrm{~V}$, was shifted only $100 \mathrm{mV}$ towards more negative potentials than on the more conductive $\mathrm{ITO}_{\mathrm{h}}$ electrode (compare with Figure 4a). Even pushing the reduction scan at $-1.7 \mathrm{~V}$ vs internal reference did not lead to the appearance of new optical patterns, but it provoked a uniform irreversible degradation of the substrate, recognizable by the decrease in the background intensity. These observations suggest that the formation of NPs is encouraged at higher conductive ITO electrode whereas the onset potential of the HER remains roughly independent of the ITO conductivity.

The dependence of the conductivity on the formation of the NPs can be related to the nature of the ITO. Indeed, $\mathrm{Sn}$ in ITO films is commonly present in $\mathrm{Sn}(\mathrm{II})$ and $\mathrm{Sn}(\mathrm{IV})$ oxidation states whose concentrations rule the film electronic conductivity [57]. The $n$-type electronic conductivity strongly depends on free electrons by the higher valent dopant $\mathrm{Sn}(\mathrm{IV})$ centers within the $\operatorname{In}_{3} \mathrm{O}_{2}$ metal oxide. On the other hand, Sn(II) centers can act as local traps of electronic conductivity, decreasing the electron transfer rate with In(III) centers and with electrolyte. This suggests that regions with locally high surface density of Sn(IV) will be more likely to form metallic In NPs at lower potential and simultaneously to consume $\mathrm{H}^{+}$ions, disfavoring the $\mathrm{H}_{2}$ NBs formation in regions where $\operatorname{In}(0)$ NPs are formed [47]. Therefore, it suggests that more conductive ITO contains higher concentration of $\mathrm{Sn}(\mathrm{IV})$. The competing role in $\mathrm{H}^{+}$consumption between HER and the NPs formation also explains the absence of NPs formation on $\mathrm{ITO}_{1}$ (Figure 6d) since the $\mathrm{H}^{+}$are most likely entirely involved in the HER reaction, also disfavoring the formation of NPs. 
Finally, the quantitative kinetics information obtained by SECM and IRM is collated in Table 1 for the different ITO substrates investigated. If the SECM in the feedback mode provides an estimate of the local electrochemical activity of the ITO and of its local resistance, the IRM imaging during a CV experiment provides, at higher throughput, similar information. Indeed, monitoring the onset of ITO reduced NP formation also likely probes the local resistance and activity of ITO surface. Interestingly the process of NB formation seems quite insensitive to the heterogeneity of conductivity for such non-catalytic support.

Table 1. Comparison of the optical monitoring of the onset of NBs or $\operatorname{In}(0)$ NPs formation with macroscale film resistance and SECM feedback.

\begin{tabular}{ccccc}
\hline Sample & Resistance $(\boldsymbol{\Omega})$ & $\mathbf{K}^{\mathbf{a}}$ & $\mathbf{E}_{\text {onset NP }}(\mathbf{V})^{\mathbf{b}}$ & $\mathbf{E}_{\text {onset,NB }}(\mathbf{V})^{\mathbf{b}}$ \\
\hline ITO $_{\mathbf{h}}$ & 40 & $1.4 / 0.3^{\mathrm{c}}$ & $-0.6 /-0.8$ & -1.2 \\
ITO $_{\mathbf{m}}$ & 150 & 0.1 & -1.05 & -1.2 \\
ITO $_{\mathbf{l}}$ & 500 & 0.02 & n.a. ${ }^{\mathrm{d}}$ & -1.2 \\
\hline
\end{tabular}

${ }^{a}$ Dimensionless finite kinetics rate from SECM with $\mathrm{FcMeOH} ;{ }^{\mathrm{b}}$ Optically inferred onset potentials (vs internal reference); measurements correspond to the median of $>100$ optical transients, the standard deviation estimated from the interquartile onset potentials distributions and internal reference potential fluctuation is \pm $50 \mathrm{mV} ;{ }^{c}$ Extreme values evaluated on the same sample from SECM feedback and optical detection of $\operatorname{In}(0)$

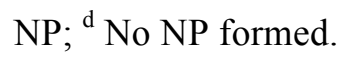

\section{Conclusion}

The electrochemical reactivity of ITO was explored under reduction conditions in the context of the opto-electrochemical monitoring of HER in a SECCM-like configuration. Beforehand, the ITO stability in acidic media was monitored optically. It evidences a degradation of the ITO at approx. $16 \mathrm{~nm} / \mathrm{min}$ in a $1 \mathrm{M} \mathrm{H}_{2} \mathrm{SO}_{4}$ and only low concentration of acid $\left(5 \mathrm{mM} \mathrm{H}_{2} \mathrm{SO}_{4}\right)$ must be used to ensure the ITO is stable long enough. 
The optical measurements performed at highly conductive ITO, while sweeping the potential toward negative values, evidence the formation of two distinct ensembles of features corresponding to the formation of two types of nanoobjects. These two populations are ascribed to the formation of $\mathrm{H}_{2} \mathrm{NBs}$ and of ITO reduced NPs issued respectively from HER and the ITO electroreduction. A detailed analysis of their optical response allowed discriminating them based on their optical characteristics. The formation of $\mathrm{H}_{2} \mathrm{NBs}$ occurs at more negative potential in random positions with a $<2 \%$ probability to nucleate at the same site between consecutive potential cycles. Moreover, the positions of the center of mass of the NBs may vary during the dynamics of their growth and dissolution, attesting of an asymmetric growth process. Besides, the reduced ITO NPs appear at less negative potential and their formation is confirmed by ex situ SEM analysis. On the contrary to NBs, $>99 \%$ NPs reappear on the same position during successive potential cycles and the center of mass displacement analysis evidences that the NPs are static all along the growth/dissolution process.

Finally, the reduction behavior of ITO electrodes strongly depends on the ITO conductivity, which may vary within a same substrate. This is demonstrated by changing the position of the droplet on a same ITO substrate or by changing the resistance of the ITO coating. The electrochemical behavior as well as the optical responses changed accordingly with the sample resistance, showing a shift in the onset potential of the formation of NPs toward less negative potentials whereas the onset potential of the HER remains mainly the same. The presence of conductive heterogeneities of a size $>50 \mu \mathrm{m}$ is further evidenced by SECM in unbiased feedback mode and explains the segregation between the NBs and the NPs formation generally observed. Ultimately, the optical imaging of the dynamics of the local formation of either reduced ITO NPs or NBs can be used as a means to rationalize local ITO conductivity. 


\section{Acknowledgements}

P. C. and F. K. acknowledge funding from the European Union's Horizon 2020 research and innovation program under the Marie Skłodowska-Curie MSCA-ITN grant agreement no. 812398, through the single entity nanoelectrochemistry, SENTINEL, project.

\section{References}

[1] N.R. Armstrong, A.W.C. Lin, M. Fujihira, T. Kuwana, Electrochemical and Surface Characteristics of Tin Oxide and Indium Oxide Electrodes, Anal. Chem. 48 (1976) 741-750. https://doi.org/10.1021/ac60368a035.

[2] O. Bierwagen, Indium oxide - A transparent, wide-band gap semiconductor for (opto)electronic applications, Semicond. Sci. Technol. $30 \quad$ (2015). https://doi.org/10.1088/0268-1242/30/2/024001.

[3] E. Fortunato, P. Barquinha, R. Martins, Oxide semiconductor thin-film transistors: A review of recent advances, Adv. Mater. $24 \quad$ (2012) 2945-2986. https://doi.org/10.1002/adma.201103228.

[4] H. Chen, T. Liu, B. Wang, Z. Liu, Y. Li, Q. Zhao, N. Wang, H. He, H. Liu, Z. Guo, Highly efficient charge collection in dye-sensitized solar cells based on nanocomposite photoanode filled with indium-tin oxide interlayer, Adv. Compos. Hybrid Mater. 1 (2018) 356-363. https://doi.org/10.1007/s42114-018-0035-4.

[5] O. Mashkov, J. Körfer, A. Eigen, A.A. Yousefi-Amin, N. Killilea, A. Barabash, M. Sytnyk, N. Khansur, M. Halik, K.G. Webber, W. Heiss, Effect of Ligand Treatment on the Tuning of Infrared Plasmonic Indium Tin Oxide Nanocrystal Electrochromic Devices, Adv. Eng. Mater. 22 (2020) 1-7. https://doi.org/10.1002/adem.202000112. 
[6] B. Zhang, G. Xu, S. Tan, C. Liu, Effects of indium-doped tin oxide film on electrochromic properties under lithium ion guidance, Opt. Mater. (Amst). 101 (2020) 109756. https://doi.org/10.1016/j.optmat.2020.109756.

[7] H. Chhina, S. Campbell, O. Kesler, An oxidation-resistant indium tin oxide catalyst support for proton exchange membrane fuel cells, J. Power Sources. 161 (2006) 893-900. https://doi.org/10.1016/j.jpowsour.2006.05.014.

[8] M. Escudero-Escribano, A. Verdaguer-Casadevall, P. Malacrida, U. Grønbjerg, B.P. Knudsen, A.K. Jepsen, J. Rossmeisl, I.E.L. Stephens, I. Chorkendorff, Pt 5Gd as a highly active and stable catalyst for oxygen electroreduction, J. Am. Chem. Soc. 134 (2012) 1647616479. https://doi.org/10.1021/ja306348d.

[9] H. Zhang, W. Zhou, Y. Du, P. Yang, C. Wang, One-step electrodeposition of platinum nanoflowers and their high efficient catalytic activity for methanol electro-oxidation, Electrochem. Commun. 12 (2010) 882-885. https://doi.org/10.1016/j.elecom.2010.04.011.

[10] M.R. Akanda, A.M. Osman, M.K. Nazal, M.A. Aziz, Review-Recent Advancements in the Utilization of Indium Tin Oxide (ITO) in Electroanalysis without Surface Modification, J. Electrochem. Soc. 167 (2020) 037534. https://doi.org/10.1149/1945-7111/ab64bd.

[11] W. Wang, Imaging the chemical activity of single nanoparticles with optical microscopy, Chem. Soc. Rev. 47 (2018) 2485-2508. https://doi.org/10.1039/C7CS00451F.

[12] B.S. Hoener, S.R. Kirchner, T.S. Heiderscheit, S.S.E. Collins, W.-S. Chang, S. Link, C.F. Landes, Plasmonic Sensing and Control of Single-Nanoparticle Electrochemistry, Chem. 4 (2018) 1560-1585. https://doi.org/10.1016/j.chempr.2018.04.009.

[13] V. Brasiliense, P. Berto, C. Combellas, G. Tessier, F. Kanoufi, Electrochemistry of Single Nanodomains Revealed by Three-Dimensional Holographic Microscopy, Acc. Chem. Res. 
49 (2016) 2049-2057. https://doi.org/10.1021/acs.accounts.6b00335.

[14] V. Brasiliense, J. Clausmeyer, P. Berto, G. Tessier, C. Combellas, W. Schuhmann, F. Kanoufi, Monitoring Cobalt-Oxide Single Particle Electrochemistry with Subdiffraction $\begin{array}{lllll}\text { Accuracy, } & \text { Anal. } & \text { Chem. } & 90 & \text { (2018) }\end{array}$ https://doi.org/10.1021/acs.analchem.8b00649.

[15] V. Sundaresan, J.W. Monaghan, K.A. Willets, Visualizing the Effect of Partial Oxide Formation on Single Silver Nanoparticle Electrodissolution, J. Phys. Chem. C. 122 (2018) 3138-3145. https://doi.org/10.1021/acs.jpcc.7b11824.

[16] J.-M. Noël, J.-F. Lemineur, Optical microscopy to study single nanoparticles electrochemistry: From reaction to motion, Curr. Opin. Electrochem. 25 (2021) 100647. https://doi.org/10.1016/j.coelec.2020.100647.

[17] J.-F. Lemineur, J.-M. Noël, A. Courty, D. Ausserré, C. Combellas, F. Kanoufi, In Situ Optical Monitoring of the Electrochemical Conversion of Dielectric Nanoparticles: From Multistep Charge Injection to Nanoparticle Motion, J. Am. Chem. Soc. 142 (2020) $7937-$ 7946. https://doi.org/10.1021/jacs.0c02071.

[18] W. Wei, T. Yuan, W. Jiang, J. Gao, H.-Y. Chen, W. Wang, Accessing the Electrochemical Activity of Single Nanoparticles by Eliminating the Heterogeneous Electrical Contacts, J. Am. Chem. Soc. 142 (2020) 14307-14313. https://doi.org/10.1021/jacs.0c06171.

[19] C.P. Byers, H. Zhang, D.F. Swearer, M. Yorulmaz, B.S. Hoener, D. Huang, A. Hoggard, W.S. Chang, P. Mulvaney, E. Ringe, N.J. Halas, P. Nordlander, S. Link, C.F. Landes, From tunable core-shell nanoparticles to plasmonic drawbridges: Active control of nanoparticle optical properties, Sci. Adv. 1 (2015) e1500988. https://doi.org/10.1126/sciadv.1500988.

[20] K. Wonner, M. V. Evers, K. Tschulik, Simultaneous Opto- and Spectro-Electrochemistry: 
Reactions of Individual Nanoparticles Uncovered by Dark-Field Microscopy, J. Am. Chem. Soc. 140 (2018) 12658-12661. https://doi.org/10.1021/jacs.8b02367.

[21] C.M. Hill, S. Pan, A Dark-Field Scattering Spectroelectrochemical Technique for Tracking the Electrodeposition of Single Silver Nanoparticles, J. Am. Chem. Soc. 135 (2013) 1725017253. https://doi.org/10.1021/ja4075387.

[22] C. Batchelor-McAuley, A. Martinez-Marrades, K. Tschulik, A.N. Patel, C. Combellas, F. Kanoufi, G. Tessier, R.G. Compton, Simultaneous electrochemical and 3D optical imaging of silver nanoparticle oxidation, Chem. Phys. Lett. 597 (2014) 20-25. https://doi.org/10.1016/j.cplett.2014.02.007.

[23] J.E. Dick, C. Renault, B.-K. Kim, A.J. Bard, Simultaneous Detection of Single Attoliter Droplet Collisions by Electrochemical and Electrogenerated Chemiluminescent Responses, Angew. Chemie Int. Ed. 53 (2014) 11859-11862. https://doi.org/10.1002/anie.201407937.

[24] R. Hao, Y. Fan, M.D. Howard, J.C. Vaughan, B. Zhang, Imaging nanobubble nucleation and hydrogen spillover during electrocatalytic water splitting, Proc. Natl. Acad. Sci. 115 (2018) 5878-5883. https://doi.org/10.1073/pnas.1800945115.

[25] S. Xu, X. Yu, Z. Chen, Y. Zeng, L. Guo, L. Li, F. Luo, J. Wang, B. Qiu, Z. Lin, Real-Time Visualization of the Single-Nanoparticle Electrocatalytic Hydrogen Generation Process and Activity under Dark Field Microscopy, Anal. Chem. 92 (2020) 9016-9023. https://doi.org/10.1021/acs.analchem.0c01129.

[26] J.-F. Lemineur, P. Ciocci, J.-M. Noël, H. Ge, C. Combellas, F. Kanoufi, Imaging and Quantifying the Formation of Single Nanobubbles at Single Platinum Nanoparticles during the Hydrogen Evolution Reaction, ACS Nano. (2021) acsnano.0c07674. https://doi.org/10.1021/acsnano.0c07674. 
[27] E. Matveeva, Electrochemistry of the Indium-Tin Oxide Electrode in $1 \mathrm{M} \mathrm{NaOH}$ Electrolyte, J. Electrochem. Soc. 152 (2005) H138. https://doi.org/10.1149/1.1984348.

[28] C.A. Huang, K.C. Li, G.C. Tu, W.S. Wang, The electrochemical behavior of tin-doped indium oxide during reduction in 0.3 M hydrochloric acid, Electrochim. Acta. 48 (2003) 3599-3605. https://doi.org/10.1016/S0013-4686(03)00480-8.

[29] L. Liu, S. Yellinek, I. Valdinger, A. Donval, D. Mandler, Important Implications of the Electrochemical Reduction of ITO, Electrochim. Acta. 176 (2015) 1374-1381. https://doi.org/10.1016/j.electacta.2015.07.129.

[30] M. Senthilkumar, J. Mathiyarasu, J. Joseph, K.L.N. Phani, V. Yegnaraman, Electrochemical instability of indium tin oxide (ITO) glass in acidic $\mathrm{pH}$ range during cathodic polarization, $\begin{array}{lllll}\text { Mater. } & \text { Chem. } & \text { Phys. } & 108 & \text { (2008) }\end{array}$ https://doi.org/10.1016/j.matchemphys.2007.10.030.

[31] S. Geiger, O. Kasian, A.M. Mingers, K.J.J. Mayrhofer, S. Cherevko, Stability limits of tinbased electrocatalyst supports, Sci. Rep. 7 (2017) 3-9. https://doi.org/10.1038/s41598-01704079-9.

[32] N. Ebejer, A.G. Güell, S.C.S. Lai, K. McKelvey, M.E. Snowden, P.R. Unwin, Scanning Electrochemical Cell Microscopy: A Versatile Technique for Nanoscale Electrochemistry and Functional Imaging, Annu. Rev. Anal. Chem. 6 (2013) 329-351. https://doi.org/10.1146/annurev-anchem-062012-092650.

[33] T.J. Stockmann, J.-F. Lemineur, H. Liu, C. Cometto, M. Robert, C. Combellas, F. Kanoufi, Single LiBH4 nanocrystal stochastic impacts at a micro water|ionic liquid interface, Electrochim. Acta. 299 (2019) 222-230. https://doi.org/10.1016/j.electacta.2018.12.105.

[34] X. Shan, I. Díez-Pérez, L. Wang, P. Wiktor, Y. Gu, L. Zhang, W. Wang, J. Lu, S. Wang, Q. 
Gong, J. Li, N. Tao, Imaging the electrocatalytic activity of single nanoparticles, Nat. Nanotechnol. 7 (2012) 668-672. https://doi.org/10.1038/nnano.2012.134.

[35] Y. Ma, A.L. Highsmith, C.M. Hill, S. Pan, Dark-Field Scattering Spectroelectrochemistry Analysis of Hydrazine Oxidation at Au Nanoparticle-Modified Transparent Electrodes, J. Phys. Chem. C. 122 (2018) 18603-18614. https://doi.org/10.1021/acs.jpcc.8b05112.

[36] J. Chen, K. Zhou, Y. Wang, J. Gao, T. Yuan, J. Pang, S. Tang, H.-Y. Chen, W. Wang, Measuring the activation energy barrier for the nucleation of single nanosized vapor bubbles, Proc. Natl. Acad. Sci. 116 (2019) 12678-12683. https://doi.org/10.1073/pnas.1903259116.

[37] Y. Wang, J. Chen, Y. Jiang, X. Wang, W. Wang, Label-Free Optical Imaging of the Dynamic Stick-Slip and Migration of Single Sub-100-nm Surface Nanobubbles: A Superlocalization Approach, Anal. Chem. $91 \quad$ (2019) 4665-4671. https://doi.org/10.1021/acs.analchem.9b00022.

[38] D. Sevenler, O. Avci, M.S. Ünlü, Quantitative interferometric reflectance imaging for the detection and measurement of biological nanoparticles, Biomed. Opt. Express. 8 (2017) 2976. https://doi.org/10.1364/BOE.8.002976.

[39] J.-F. Lemineur, J.-M. Noël, C. Combellas, F. Kanoufi, Revealing the sub-50 ms electrochemical conversion of silver halide nanocolloids by stochastic electrochemistry and optical microscopy, $\quad$ Nanoscale. $\quad 12 \quad$ (2020) $\quad 15128-15136$. https://doi.org/10.1039/D0NR03799K.

[40] J.C. Crocker, D.G. Grier, Methods of digital video microscopy for colloidal studies, J. Colloid Interface Sci. (1996). https://doi.org/10.1006/jcis.1996.0217.

[41] D. Allan, T. Caswell, N. Keim, C. Van Der Wel, trackpy: Trackpy v0.3.2. Zenodo. http://doi.org/10.5281/zenodo.60550, trackpy: Trackpy v0.3.2, Zenodo. (2016). 
[42] S. Amemiya, A.J. Bard, F.R.F. Fan, M. V. Mirkin, P.R. Unwin, Scanning electrochemical microscopy, Annu. Anal. $\quad$ Rev. Chem. (2008). https://doi.org/10.1146/annurev.anchem.1.031207.112938.

[43] G. Wittstock, M. Burchardt, S.E. Pust, Y. Shen, C. Zhao, Scanning Electrochemical Microscopy for Direct Imaging of Reaction Rates, Angew. Chemie Int. Ed. 46 (2007) 15841617. https://doi.org/10.1002/anie.200602750.

[44] R. Cornut, C. Lefrou, New analytical approximation of feedback approach curves with a microdisk SECM tip and irreversible kinetic reaction at the substrate, J. Electroanal. Chem. 621 (2008) 178-184. https://doi.org/10.1016/j.jelechem.2007.09.021.

[45] J.E.A.M. van den Meerakker, P.C. Baarslag, M. Scholten, On the Mechanism of ITO Etching in Halogen Acids: The Influence of Oxidizing Agents, J. Electrochem. Soc. 142 (1995) 2321-2325. https://doi.org/10.1149/1.2044294.

[46] S. Li, M. Tian, Q. Gao, M. Wang, T. Li, Q. Hu, X. Li, Y. Wu, Nanometre-thin indium tin oxide for advanced high-performance electronics, Nat. Mater. 18 (2019) 1091-1097. https://doi.org/10.1038/s41563-019-0455-8.

[47] E.R. Spada, F.R. De Paula, C.C. Plá Cid, G. Candiotto, R.M. Faria, M.L. Sartorelli, Role of acidic and basic electrolytes on the structure and morphology of cathodically reduced indium tin oxide (ITO) substrates, Electrochim. Acta. $108 \quad$ (2013) 520-524. https://doi.org/10.1016/j.electacta.2013.06.077.

[48] S. Shen, X. Zhang, S. Mubeen, M.P. Soriaga, J.L. Stickney, Optimization of the nucleationsite density for the electrodeposition of cadmium sulfide on indium-tin-oxide, Electrochim. Acta. 316 (2019) 105-112. https://doi.org/10.1016/j.electacta.2019.05.120.

[49] S.R. German, M.A. Edwards, H. Ren, H.S. White, Critical Nuclei Size, Rate, and Activation 
Energy of H2 Gas Nucleation, J. Am. Chem. Soc. 140 (2018) 4047-4053. https://doi.org/10.1021/jacs.7b13457.

[50] Y. Liu, C. Jin, Y. Liu, K.H. Ruiz, H. Ren, Y. Fan, H.S. White, Q. Chen, Visualization and Quantification of Electrochemical H 2 Bubble Nucleation at Pt, Au, and MoS 2 Substrates, ACS Sensors. (2020) acssensors.0c00913. https://doi.org/10.1021/acssensors.0c00913.

[51] J. Ustarroz, J.A. Hammons, T. Altantzis, A. Hubin, S. Bals, H. Terryn, A Generalized Electrochemical Aggregative Growth Mechanism, J. Am. Chem. Soc. 135 (2013) 11550 11561. https://doi.org/10.1021/ja402598k.

[52] M.A. Edwards, H.S. White, H. Ren, Voltammetric Determination of the Stochastic Formation Rate and Geometry of Individual H 2, N 2 , and O 2 Bubble Nuclei, ACS Nano. 13 (2019) 6330-6340. https://doi.org/10.1021/acsnano.9b01015.

[53] D. Lohse, X. Zhang, Surface nanobubbles and nanodroplets, Rev. Mod. Phys. 87 (2015) 981-1035. https://doi.org/10.1103/RevModPhys.87.981.

[54] G. Gökçeli, N. Karatepe, Investigation of hydrogen post-treatment effect on surface and optoelectronic properties of indium tin oxide thin films, J. Alloys Compd. 851 (2021). https://doi.org/10.1016/j.jallcom.2020.156861.

[55] S. Bouden, A. Dahi, F. Hauquier, H. Randriamahazaka, J. Ghilane, Multifunctional Indium Tin Oxide Electrode Generated by Unusual Surface Modification, Sci. Rep. 6 (2016) 1-9. https://doi.org/10.1038/srep36708.

[56] J.-F. Lemineur, J.-M. Noël, D. Ausserré, C. Combellas, F. Kanoufi, Combining Electrodeposition and Optical Microscopy for Probing Size-Dependent Single-Nanoparticle Electrochemistry, Angew. Chemie Int. Ed. $57 \quad$ (2018) 11998-12002. https://doi.org/10.1002/anie.201807003. 
[57] K.-S. Park, Y.-J. Choi, J.-G. Kang, Y.-M. Sung, J.-G. Park, The effect of the concentration and oxidation state of $\mathrm{Sn}$ on the structural and electrical properties of indium tin oxide nanowires, Nanotechnology. $22 \quad$ (2011) 285712. https://doi.org/10.1088/0957$4484 / 22 / 28 / 285712$. 